\title{
III.
}

\section{Darstellung von reinem Barythydrat aus kohlensaurem Baryt unter dem Einfluss überhitzten Wasserdampfes.}

Von

\section{V.A. Jacquelain.}

(Annales de Chimie et de Phys. lom XXXII. 421.)

Genaue Versuche traben mir erlaubt zu zeigen, dass dàs kohlensaure Kali und Natron eine beträchtliche Menge Kohlensäure verlieren, wenn sie, bis zum dunklen Rothglühen erhitż, der gleichzeitigen Einwirkung eines Stromes von übcrhitztem Wasserlampf oder Kohlensüure ausgesetzt werden.

Nach Feststellung dieser Thatsache lag es mir daran, cine vollständige Austreibung der Kohlensüure aus diesen beiden Salzen durch die Gegenwart von Wasserdampf zu bewirken; denn bewährte sich dieser Versuch, so war es wahrscheinlich, dass es mir gelingen würde, eine Erscheinung derselben Art auch beim kohlensauren Baryt zu erhalten, welcher nach meinen Versuchen bei hoher Temperatur eine grōssere Beständigkeit zeigte, als der kohlensaure Kalk, eine geringere aber, als das kohlensaure Kali und Natron.

Zu diesem Zweck machte ich eine Mischung von $65 \mathrm{Grm}$. wasserfreiem kohlensauren Natron und $250 \mathrm{Grm}$. Kreide. Dem Ganzen wurde eine hinreichende Menge Wasser zugesetzt, um daraus kleine, wenig zusammenhängende Knollen formen zu können. Diese Mischung wurde bei Rothglühlitze erhalten, und 6 Stunden lang Wasserdampf darüber geleitet, welcher, unter gewöhnlichem Luftdruck erzeugt, langsam durchging, um das Fortreissen des Alkalis zu vermindern. Nach Verlauf dieser Zeit war die Kohlensäure vollstăndig ausgetrieben.

Die alkalimetrische Probe, welche zur Bestimmung des in ılem Gemisch zurückgebliebenen Aetznatron angestellt wurde, ergab 95 anstatt 100 des zersetzten kohlensauren Natrons. Da nun in der geglühten Masse keine Spur von Kohlensäure zu entdecken war, so schloss ich daraus, dass die $\breve{5}$ von den 100 
des kohlensauren Natrons von den Wïnden der Porcellanrơhlre aufgenommen und in Natronsilikat verwandelt worden seien.

Die Hauptbedingung des Erfolgs bei dieser 0 0 peration ist die Erhaltung der Massen in schwammiger Form, welcher Zustand der Vertheilung durch den Kalk leicht berwirkt wird, inlem er das schmelzende kohlensaure Natron einsaugt.

Diesen sinnreichen Kunstgriff verdanken wir Dumas, welcher eine schicklichere Mischung derjenigen unterlegte, welchc Persoz zur Bereitung des Sumpfgases anempfohlen hatte. Will und Varrentrapp haben hierauf die beste Anwendung vom Natronkalk bei der Analyse organischer stickstoflaltiger Körper gemacht. Endlich wird man bald sehen, dass mir vor Boussingault ein ähnliches Mittel zur Bercitung des Baryts gedient hat.

Seit dem Jahre 1850, kurz nach Verouffentlichung meiner Arbeit über die kohlensauren Salze, unternahm ich die Versuche, welche ich hier im Auszug gebe, Ich lasse sie so auf einanter folgen, wie ich sie in meinem Arbeitshuch aufgezeichnet habe.

Alle Jlischungen wurden in ein langes Schiffehen von Platin gebracht, und dieses in eine weite Porcellanröhre gelegt. An das eine Ende wurde eine Retorte angefügt, welche langsam kochendes Wasser enthielt; mit dem entgegengesetzten Ende wurde eine Gas - und Sicherheitsröhre in Verbindung gebracht. Der Versuch dauerte stets 4 Stunden.

\section{Erster Versuch.}

123,3 Grm. $\left.\mathrm{BaO}, \mathrm{CO}_{2}\right)$ Entwicklung von $\mathrm{H}$ und $\mathrm{CO}_{2}$; die Mischung $62,5 \mathrm{Grm}$. $\mathrm{CaO}_{2} \mathrm{CO}_{2}$ halb geschmolzen; von 100 angewandten 7,5 Grm. C.

\section{Zweiter Versuch.}

$123,3 \mathrm{Grm} . \mathrm{BaO}, \mathrm{CO}_{2}$ Entwicklung von Kohlensäure; die Mischung 62,5 Grm. $\mathrm{CaO}, \mathrm{CO}_{2}$ halb geschmolzen; von 100 angewandtem kohlensauren Baryt waren 30 zersetzt.

Diese beiden Versuche lelıren uns: 1. dass ein grosser Theil des kohlensauren Baryts durch Umhüllung von geschmolzenem Baryt der Einwirkung des Wasserdampfes entgeht; 2. dass bei Anwendung von Kohle die Einwirkung des Wasserdampfes vermindert wird; in dem Verhältniss nämlich, als, sich kohlensaurer Baryt zersetzt, trennt die Kohle die Bestandtheile 
des Wassers und erzeugt von Neuem Kohlensüure nebst Wasserstoff, deren Gegenwart dem Erfolg des Versuches schadet, wie wir bald sehen werden.

\section{Dritter Versuch.}

123,3 Grm. BaO, $\mathrm{CO}_{2} \mid$ Etwas porõse Masse; 50 von 100 ange$125,0 \mathrm{Gr} . \mathrm{CaO}, \mathrm{CO}_{2}$ wandtem kohlensauren Baryt waren zer$7,5 \mathrm{Grm}$. C. setzt.

Vierter Versuch.

$123,3 \mathrm{Grm} . \mathrm{BaO}, \mathrm{CO}_{2} \backslash$ Etwas poruse Masse; von 100 angewandtem $125,0 \mathrm{Grm}$. $\mathrm{CaO}, \mathrm{CO}_{2}$ ) kohlensauren Baryt waren 90 zersetzt.

Vierter Versuch (wiederholt).

123,3 Grm. $\left.\mathrm{BaO}, \mathrm{CO}_{2}\right\}$ Die Masse poróser; von 100 angewandtem $190,0 \mathrm{Grm}$. $\left.\mathrm{CaO}, \mathrm{CO}_{2}\right\}$ kohlensauren Baryt warm 90 zersetzt.

Nach diesen Resultaten stellte ich im Monat August 1850 bei Robert de Massy, Destillateur zu Racourt bei St. Quentin die drei folgenden Versuche an.

Der Apparat bestand aus drei gusseisernen Cylindern von 2,5 Meter Länge und 7 Centimeter Weite. Sie wurden alle drei auf eine ebene Fläche in einen mit Steinkohlen geheizten Ofen von Mauerwerk so gelegt, dass sie etiva 10 Centimeter von einander abstanden. Durch jede Röhre strömte Wasserdampf aus einem Dampfkessel. Die drei Apparate wurden durch Röhren mit Hähnen von einander unabhängig gemacht, um nach Belieben den Dampfstrom zu regein oder abzuschliessen. Der mittlere Cylinder mit kohlensaurem Baryt und Kohle erhielt keinen Wasserdampf.

Das entgegengeselzte Ende jedes Cylinders endigte in eine kupferne Rölre, welche die gasförmigen Produkte in eine Art Wasserwanne führte, um sie der Analyse unterwerlen zu kōnnen.

\section{Fünfter Versuch.}

$\left.120,0 \mathrm{rm} . \mathrm{BaO}, \mathrm{CO}_{2}\right)$ Nach sechsstündigem Feuer war die Masse $\left.120,0 \mathrm{Grm} ; \mathrm{CaO}, \mathrm{CO}_{2}\right\}$ weiss, porös, sie enthielt sehr wenig Aetz20,0 Grm. C.

Sechster Versuch.

$\left.\begin{array}{l}120,0 \mathrm{Grm} . \mathrm{BaO}, \mathrm{CO}_{2} \\ \text { 20,0 Grm. C. }\end{array}\right\}$ Keine Zersetzung.
. 


\section{Siebenter Versuch.}

$\left.120,0 \mathrm{Grm} . \mathrm{BaO}, \mathrm{CO}_{2}\right\}$ Weisse poröse Masse, von 100 kohlen $\left.120,0 \mathrm{Grm} . \mathrm{CaO}, \mathrm{CO}_{2}\right\}$ saurem Baryt waren 40 zersetzt.

Man ersieht aus diesen Resultaten, dass zur Zersetzung des kohlensauren Baryts durch Kohle eine hülıcre Temperatur nöthig ist, als zur Zersetzung mil überhitzten Wasserdämpfen erfordert wird.

Ferner haben der fünfte und siebente Versuch weniger Baryt geliefert, als der entsprechende dritte und vierte, welche letztern Versuche in meinem Laboratorium angestellt wurden.

Die beteutende Abweichung schreibe ich der Zersetzung zu, welche eine gewisse Menge Wasserdampf durch die Iände des eisernen Cylinders erlitt.

Um die Circulation des Wasserdampfes zu verlangsamen und ihn besser zu erhitzen, war ich genöthigt, den Strom durch eine sehr kleine Oeffnung des Hahnes gehen zu lassen. Man begreift dann, dass die Wirkung des gesammten Wasserdampfes, welche in einer gewissen Zeit thätig war, durch die ganze Menge Wasser vermindert wurde, wclche die eisernen Wände zersetzten.

Ich wiederholte den siebenten Versuch genau wie zuerst in meinem Laboratorium, indem ich nümlich den Dampf ganz langsam über ein Gemenge von $2400 \mathrm{Grm}$. gehen liess, welches sich diesmal in einer Rōhre von undurchuringlichem Steingut befand, Nach sechsstündigem Feuer hatte ich $88 \%$ des angewandten kohlensauren Baryts zersetzt.

Ich füge schliesslich hinzu, dass alle diese Versuche mit Kalkhydrat wiederholt worden sind, und denselben Erfolg in einer etwas kürzeren Zeit gehabt haben.

Man kann demnach nach Belieben vom Kalk oder kohlensauren Kalk Gebrauch machen. Der Vorzug in einem solchen Falle wird nur durch den Unterschied des Kostenaufwandes bedingt, welcher zwischen dem kohlensauren Kalk, bei einer etwas längeren Dauer des Versuchs, und dem Aetzkalk, bei einer kürzeren Operation, staltindet.

Die Versuche, welche Boussingault über die höhere Oxydation des Baryts und die theiliveise Desoxydation des Bariumhyperoxyds bekannt gemacht hat, sind von derselben Art ,wie die, welche Lavoisier zur Zusammensetzung der Luft 
geführt haben, der das Quecksilber abwechselnd oxydirte und desoxydirte. Sie verdienen aber einen hohen Grad von Aufmerksamkeit, da sie später einmal in den Gewerben unter Mitwirkung einer Base von geringerem Werth, als die des Quecksilbers, Anwendung finden könnten. Bis gegenwärtig musste man das Barythydrat aus einem Gemisch von kohlensaurem Baryt mit Kohle bereiten; die geglühte Masse musste dann ausgelaugt und die Lüsung zur Trockne verdampft werden. Jetzt aber macht man ganz einfach ein Gemisch von Kreide oder Kalk mit natürlichem oder künstlichem kohlensauren Baryt, und erhält zuletzt ein porüses Gemenge von Aetzkalk, getränkt mit Barythydrat, weicher sich unter den günstigsten Bedingungen befindet, um eine höhere Oxyclation zu erleiden, olne dass man nöthiğ hätte, das Gefäss zu wechseln und das Barythydrat vorher auszuziehen.

Die eben erwähnten Arbeiten sind so einfach, dass sic der Ausgangspunkt zur Bereitung des reinen Baryts für die Industrie werden können.

Ich muss noch hinzüügen, dass die Carbonate von Litlion und Strontian sich gegen den überhitzten Wasserdampf ebenso verhalten, wie die des Kali und Baryts, was für die Anwendung von Strontiansalzen zur Feuerwerkskunst von einigem Nutzen sein kann.

Schliesslich gebe ich einige Andeutungen für die Ausführung meines Verfahrens in Grossen.

Die Bereitung des Baryts würde in feuerfesten Thonretorten, von der Form und Grösse der Gasretorten, vorzunehmen sein. Die Mischung des kohlensauren Baryts mit Kreide und Kalk und ihr Befeuchten liesse sich in einer Tonne ausführen, welche um eine horizontale Axe bewegt würde. Die Füllung und Entleerung der Retorte geschähe nach gewöhnlicher Art.

Man könnte die Wärme benutzen, welche das Gemisch nach der Entfernnng aus der Retorte erlangt bat, eben so wie die, welche sich bei der chemischen Einwirkung des Wassers auf die Mischung entwickelt, um unmittelbar das Wasser zu erhitzen, welches nach gewöhnlicher Art des Auslaugens den ganzen Baryt ausziehen und gehörig concentrirte Losungen liefern soll.

Der Dampf darf sich nicht mit Heftigkeit erzeugen, sondern muss vielmehr freı aus dem Behälter ausstrōmen, und langsam über das schwach rothglühende Gemenge der Carbonate streichen. 
Es würde daber genügen, in die Năhe des Ofens einen Siedekessel zu stellen, welcher mit dem Deckel einer jeden Retorte durch weite Röhren in Verbindung stellt und alle Retorten mit Wasserdämpfen versieht.

Endlich künnte man die erzeugte Kohlensüure benutzen, wenn man sie in Wasser leitete, welches Zuckerbaryt vertheilt enthält. Ebenso künnte man das Kalkhydrat, aus welchem durch Auslaugen der Baryt vorher entfernt ist, mit dem kohlensauren Baryt mengen, welcher durch die Zersetzung des Zuckerbaryts mittelst Kohlensüure entstanden ist. Man würde so eine nette kürnige Masse zur Füllung der Retorte erhalten, nachdem sic in der Wärme des Mauerwerks der Oefen getrocknet worden wäre.

\title{
IV. \\ Ergebnisse chemischer Untersuchungen einiger Bimssteine.
}

\author{
Von
}

\section{Dr. T. R. Schäiffer.}

(Aus dessen Dissertation: Ueber die Bimssteinküner bei Marburg in Hessen. Marburg 1851.)

Der Bimsstein ist, wie bekannt, nur ein blasiges, aus Trachyt entstandenes Obsidianglas. Es lässt sich demnach eine Uebereinstimmung in der Zusammensetzung der Bimssteine nicht crwarten. Sehr richtig bemerkt daber auch Rammelsberg: "Wahrscheinlich sind es mehrere Verbindungen, welche die „Grundlage des Bimssteins ausmachen, und man darf diesen „Namen vielleicht mehr für einen bestimmten Zustand als für "eine bestimmte Verbindung gebrauchen."

Zur Vergleichung folgen hier die bis jetzt bekannten Analysen von Obsidian, Trachỵt und Bimsstein, wie sie Rammelsberg anführt: 